\title{
Evidence for Anti-vascular Endothelial Growth Factor Treatment of Diabetic Macular Oedema
}

\author{
Francesco Bandello, ${ }^{1}$ Umberto De Benedetto, ${ }^{1}$ Karl Anders Knutsson,
} Maurizio Battaglia Parodi, ${ }^{1}$ Maria Lucia Cascavilla ${ }^{1}$ and Pierluigi Iacono ${ }^{2}$

1. Department of Ophthalmology, Vita-Salute University, San Raffaele Scientific Institute, Milan; 2. GB Bietti Ophthalmology Foundation, Rome

\begin{abstract}
Diabetic macular oedema (DME) represents the most common cause of vision loss in patients affected by diabetes mellitus. Diabetic retinopathy has a significant impact on public health and the quality of life of many patients and thus requires serious consideration. The first line of treatment remains the management of systemic risk factors but this is often insufficient in controlling DME and currently, laser retinal photocoagulation is considered the standard of care. However, laser treatment reduces the risk of moderate visual loss by approximately $50 \%$ without guaranteeing remarkable effects on visual improvement. For these reasons, new approaches in the treatment of DME have been considered, in particular the employment of anti-vascular endothelial growth factor (VEGF) drugs. VEGF is a pluripotent growth factor that functions as a vasopermeability factor and an endothelial cell mitogen and thereby represents an appealing candidate as a therapeutic target for the treatment of DME. The goal of this article is to present the evidence behind the use of anti-VEGF drugs in the treatment of DME.
\end{abstract}

\section{Keywords}

Diabetic macular oedema, anti-vascular endothelial growth factor, ranibizumab, bevacizumab, pegaptanib, anti-vascular endothelial growth factor Trap-Eye, bevasiranib, rapamycin

Disclosure: Francesco Bandello is a consultant for Novartis, Allergan, Pfizer, Alcon, Bayer and Thea. The remaining authors have no conflicts of interest to declare. Received: 1 August 2011 Accepted: 13 September 2011 Citation: European Endocrinology, 2012;8(1):36-41 DOl:10.17925/EE.2012.08.01.36 Correspondence: Francesco Bandello, Department of Ophthalmology, Vita-Salute University, San Raffaele Scientific Institute, Via Olgettina 60, 20132 Milan, Italy. E: bandello.francesco@hsr.it

Diabetic retinopathy is considered the most frequent retinal vascular disorder and is detectable in about $40 \%$ of diabetic patients 40 years of age and older. ${ }^{1}$ Today, diabetic retinopathy is the leading cause of acquired blindness among young adults throughout developed countries. ${ }^{2}$ Population-based epidemiological studies have estimated that, after 20 years, diabetic retinopathy can be identified at least to a certain extent and that, after 30 years, proliferative diabetic retinopathy is present in $70 \%$ of patients with diabetes mellitus type $1 .{ }^{3}$ The World Health Organization (WHO) estimates that about 171 million people are affected by diabetes with a likely doubling of the prevalence within 20 years. ${ }^{4}$ Diabetic macular oedema (DME) is the major cause of visual acuity (VA) impairment secondary to diabetic retinopathy.

DME is generally defined as retinal thickening or presence of hard exudates within one disk diameter from the centre of the macula. ${ }^{5}$ During past years, many therapeutic strategies have been proposed for the treatment of DME including focal/grid laser photocoagulation, ocular steroids, intravitreal anti-vascular endothelial growth factor (VEGF) drugs and vitreo-retinal surgery. VEGF is a pluripotent growth factor that acts as an endothelial cell-specific mitogen and vasopermeability factor, playing a critical role in promoting angiogenesis and vascular leakage..$^{6-10}$ In diabetic retinopathy, the alteration of the blood-retinal barrier and increased permeability are responsible for the development of DME. VEGF increases the extracellular accumulation of fluid from the intravascular compartment by disrupting the intercellular tight junctions between retinal endothelial cells. ${ }^{8-11}$ The pathway between VEGF gene transcription and the activation of the VEGF receptor is the object of the new therapeutic approaches based on the use of VEGF antagonists. Pegaptanib, ranibizumab, bevacizumab and VEGF Trap are molecules able to directly bind the VEGF protein. A new and interesting therapeutic approach is the employment of bevasiranib. This molecule, interfering with messenger RNA (mRNA), interrupts the synthesis of the VEGF protein. Lastly, rapamycin, commonly employed as an immunosuppressive, anti-inflammatory, or antimycotic drug, reduces the activity of the VEGF molecule, interfering with the promoting signal and the active synthesis of VEGF and reducing the response of endothelial cells to VEGF. The aim of this article is to review the role of anti-VEGF drugs in the treatment of DME.

\section{Ranibizumab}

Ranibizumab is an antigen-binding fragment (Fab) derived from a humanised anti-VEGF antibody that inhibits all biologically active isoforms and active proteolytic fragments of VEGF-A. Many clinical investigations have shown its efficacy in the treatment of DME.

In the first pilot study, two dosing regimens of ranibizumab (0.3 and $0.5 \mathrm{mg}$ ) were used in 10 patients affected by clinically significant DME. ${ }^{12}$ At month three, $40 \%$ of patients gained more than 15 letters, $50 \%$ gained more than 10 letters, and $80 \%$ obtained an improvement of at least one letter in best corrected visual acuity (BCVA) and a decrease in central retinal thickness (CRT) was detected in both groups. 
Nguyen et al. investigated the role of ranibizumab in DME in the open-label study Ranibizumab for oedema of the macula in diabetes: Phase I (READ-1). ${ }^{13}$ Ten patients with chronic DME received intraocular injections of $0.5 \mathrm{mg}$ ranibizumab at baseline and at one, two, four and six months. Mean and median values of BCVA improved at seven months by 12.3 and 11 letters, respectively, and foveal thickness showed a significant reduction.

Recently, the results of the second phase of the READ study ${ }^{14,15}$ (READ-2, a phase II, prospective, randomised clinical trial conducted at 14 sites in the US) were reported. The aim of this study was to compare ranibizumab with focal/grid laser, alone or in combination. One hundred and twenty-six patients were randomised to receive $0.5 \mathrm{mg}$ ranibizumab (group 1, $\mathrm{n}=42$ ), focal/grid laser photocoagulation (group 2, n=42) or a combination of $0.5 \mathrm{mg}$ ranibizumab and focal/grid laser (group 3, n=42). Baseline characteristics were well balanced in the randomisation groups. Subjects with BCVA between 20/40 and 20/320 due to DME and CRT of $250 \mu \mathrm{m}$ or more were recruited. Patients in the ranibizumab group received an injection at baseline and months one three and five. Patients in the laser group received focal or grid laser photocoagulation at baseline and again at month three if central subfield thickness (CST) was $250 \mu \mathrm{m}$ or more. At baseline and month three, patients in the combined therapy group received an intraocular injection of ranibizumab followed by focal or grid laser treatment one week later.

At month six, the group receiving ranibizumab alone showed a significant improvement in mean BCVA compared with patients receiving focal/grid laser. BCVA in the group receiving combined therapy was not statistically different from the other groups. A resolution of 50,33 , and $45 \%$ of excess foveal thickening was observed, respectively, in the three groups after six months. After the primary endpoint (six months), patients in all groups were seen every two months, and if they had persistent or recurrent DME, defined as CRT of $250 \mu \mathrm{m}$ or more, patients in group 1 could receive an intraocular injection of $0.5 \mathrm{mg}$, patients in group 2 ranibizumab alone or laser, and patients in group 3 ranibizumab alone or combined with laser. The two-year outcomes of READ-2 showed an improvement in BCVA of 7.7, 5.1 and 6.8 letters compared with baseline in groups 1, 2 and 3 , respectively. CRT at month 24 was 340,286 and $258 \mu \mathrm{m}$ for groups 1,2 and 3 , respectively, and the percentages of patients with CRT of $250 \mu \mathrm{m}$ or less were 36,47 and $68 \%$. The mean number of injections was 5.3, 4.4 and 2.9 in the respective groups. Twenty-eight patients were left the study before the two-year endpoint: 10 in group 1, eight in group 2 and 10 in group 3.

The study reported a single case of severe adverse event: one subject died of a cerebrovascular accident six weeks after the first ranibizumab injection. This event was considered unrelated to ranibizumab because of pre-existent cardiovascular pathology and because a long period elapsed between injection and vascular event. No statistically significant differences in mean systolic and diastolic blood pressure were found between the groups. Ocular adverse events included vitreous haemorrhages in eight patients. The visual outcomes of the READ-2 study at month 24 were not significantly different in the three treatment groups, whereas the anatomical outcomes were better, with fewer injections of ranibizumab in groups 2 and 3 . This suggests that the additional focal/grid laser treatment in groups 2 and 3 helped to reduce persistent or recurrent macular oedema as well as the number of ranibizumab injections required.
The Randomised, double-masked, multicenter, phase ॥ study assessing the safety and efficacy of two concentrations of ranibizumab compared with non-treatment control for the treatment of diabetic macular oedema with center involvement (RESOLVE) trial evaluated the effect of ranibizumab on retinal oedema and VA in 151 patients with clinically significant DME. Patients with central macular thickness (CMT) of $300 \mu \mathrm{m}$ or greater were randomised to receive three monthly injections of either 0.3 or $0.5 \mathrm{mg}$ ranibizumab or placebo and afterwards on a pro re nata (PRN) basis for nine months; retinal photocoagulation could be administered if needed. After month one, the ranibizumab dose (or sham) could be doubled by increasing the injection volume from 0.05 to $0.1 \mathrm{ml}$ based on specific CMT criteria. When injection volume was increased to $0.1 \mathrm{ml}$, subsequent administrations remained at $0.1 \mathrm{ml}$ with a double dose (0.6 or $1.0 \mathrm{mg}$ ranibizumab). Baseline characteristics were similar in the ranibizumab and sham arms. However, there were more discontinuations in the sham arm than in the ranibizumab arm (18.4 and $9.8 \%$, respectively). During the 12 months of follow-up, the mean BCVA increased and mean CMT decreased continuously over time. The groups receiving $0.3 \mathrm{mg}$ and $0.5 \mathrm{mg}$ gained, respectively, 11.8 letters and 8.8 letters $^{16}$ and pooled data (including both dosing regimens) showed a gain of 10.3 letters. ${ }^{17}$ The RESOLVE study showed that there are no imbalances in the rates of ocular and non-ocular severe adverse effects (SAES) or adverse effects (AES) between patients receiving ranibizumab and those receiving sham injections. Most of the SAEs were non-ocular in origin (ranibizumab, 14 [13.7\%]; sham, 8 [16.3\%]). Two cases of endophthalmitis occurred. Also, the rate of subjects reporting non-ocular AEs was comparable between the ranibizumab and sham arms. One of the limitations of the study was the absence of a laser treatment arm; patients could receive rescue laser photocoagulation after three months. Approximately 5 and $35 \%$ of patients received laser treatment in the ranibizumab and sham arms, respectively. However, the effect of laser on BCVA was not evaluated. In conclusion, the study confirmed the efficacy of ranibizumab in improving BCVA in patients with DME.

The Ranibizumab monotherapy or combined with laser versus laser monotherapy for diabetic macular edema (RESTORE) study, ${ }^{18}$ a 12-month, phase III, randomised, double-masked, multicentre, sham-controlled, laser-controlled trial, included 345 patients affected by DME randomised to three groups: ranibizumab and sham laser $(n=116)$, ranibizumab and laser photocoagulation $(n=118)$, or sham injections and laser $(n=111)$. Ranibizumab/sham was given for three months and then on a PRN basis; laser/sham laser was performed at baseline then PRN. The percentages of patients with complete follow-up were similar in the three groups: $87.9 \%$ (ranibizumab), $87.3 \%$ (ranibizumab + laser) and $88.3 \%$ (laser). Baseline and diabetes characteristics were comparable across the three treatment arms. After 12 months, a significantly greater proportion of patients had a BCVA letter score $\geq 15$ and BCVA letter score level $>73$ (20/40 Snellen equivalent) with ranibizumab (22.6 and $53 \%$, respectively) and ranibizumab + laser (22.9 and $44.9 \%$ ), versus laser (8.2 and $23.6 \%$ ). At one year of follow-up, no significant differences were detected between ranibizumab monotherapy and ranibizumab associated with laser photocoagulation. In the RESTORE study ${ }^{18}$ no cases of endophthalmitis were reported. Increased intraocular pressure was reported for one patient each in the ranibizumab arms. No increased risk of cardiovascular or cerebrovascular events was documented in this study. Overall, the RESTORE study demonstrates that ranibizumab monotherapy provides superior outcomes compared 
with standard-of-care treatment in patients with visual impairment due to DME. Long-term results are awaited to evaluate the outcomes of laser treatment alone and in combination with ranibizumab. The study has a limited follow-up to allow a real efficacy comparison with laser treatment, the latter being slower in producing its effects.

It is well known that corticosteroids play an important role in reducing $\mathrm{DME}^{19,20}$ by decreasing the release of arachidonic acid derivatives such as prostaglandins, responsible for altered retinal vascular permeability and by inhibiting VEGF production. In order to provide further clarity on the effectiveness of treatments based on administration of steroidal or anti-VEGF drugs in comparison with conventional laser treatment, the Diabetic Retinopathy Clinical Research Network (DRCRnet) designed a randomised, multicentre clinical trial. ${ }^{21,22}$ The study (two years follow-up) recruited 691 patients and examined a total of 854 eyes randomised in four groups receiving: laser photocoagulation treatment alone (293 eyes), $0.5 \mathrm{mg}$ ranibizumab + prompt laser (187 eyes), $0.5 \mathrm{mg}$ ranibizumab + deferred laser (at least 24 weeks, 188 eyes), or intravitreal triamcinolone $4 \mathrm{mg}+$ prompt laser (186 eyes). At one-year examination, the mean change in the VA letter score with respect to the baseline value showed a statistically significant improvement in the ranibizumab + prompt laser group $(+9 \pm 11$ letters $)$ and ranibizumab + deferred laser group $(+9 \pm 12)$, but not in the triamcinolone + prompt laser group $(+4 \pm 13)$, compared with the laser group $(+3 \pm 13)$. Over the two years of follow-up, a different correlation between VA change and retinal thickness was observed in each group. A progressive reduction in mean CST was noted in the laser group during the 24 months of follow-up; however, the mean change in VA did not continue to increase from the one- to two-year visit as noted during the first year of follow-up. In the triamcinolone + laser group, during the first year of follow-up, an improvement of visual function was associated with a significant reduction in CST, whereas, from the one- to two-year examination, the mean CST increased in parallel with a VA reduction. Ranibizumab groups showed a parallel VA improvement associated with a CST reduction from baseline to the 12-month visit and, following this period, the optical coherence tomography (OCT) results remained relatively stable up to the 24-month examination and paralleled the VA outcomes. Intraocular hypertension and cataract surgery were more frequently noted in the triamcinolone + prompt laser group in comparison with groups receiving ranibizumab + laser or laser alone. This trial confirms the promising preliminary results in the treatment of DME, suggesting that a combined therapy might offer a more efficient approach considering the multifactorial pathogenesis of the disorder. Moreover, it is once again demonstrated that laser treatment requires many months to become active on DME.

The Study of ranibizumab injection in subjects with clinically significant macular oedema with centre involvement secondary to diabetes mellitus ([RISE] [ $n=377]$ and [RIDE] [ $n=382]$ ) trials are Phase III, double-masked, multicentre, randomised, sham injection-controlled trials evaluating the efficacy and safety of ranibizumab injections in patients with DME. ${ }^{23}$ Patients were randomised into three groups: sham injections (RISE [ $n=127]$, RIDE $[n=130]$ ), ranibizumab $0.3 \mathrm{mg}$ injections (RISE $[n=125], \operatorname{RIDE}[n=125]$ ), and ranibizumab $0.5 \mathrm{mg}$ injections (RISE [ $n=125]$, RIDE [ $n=127]$ ). The primary outcomes assessed are the percentage of subjects who gain at least 15 letters in BCVA compared with baseline, mean change from baseline in BCVA and mean change from baseline in central foveal thickness (CFT). The preliminary results report that patients gaining at least three lines compared with baseline were 18.1, 44.8 and $39.2 \%$ in RISE and 12.3, 33.6 and $45.7 \%$ in RIDE, in the sham, $0.3 \mathrm{mg}$ ranibizumab, and $0.5 \mathrm{mg}$ ranibizumab groups, respectively. Patients achieving a VA of at least $20 / 40$ were $37.8,60$, and $63.2 \%$ in RISE and 34.6, 54.4, and $62.2 \%$ in RIDE, in the sham, $0.3 \mathrm{mg}$ ranibizumab, and $0.5 \mathrm{mg}$ ranibizumab groups, respectively. Two-year data analysis from the two studies showed an ocular and general safety profile similar to previous trials, with no systemic AEs due to ranibizumab injections.

\section{Pegaptanib}

Pegaptanib is a pegylated 28-nucleotide RNA aptamer that binds to the VEGF164/165 isoform at high affinity. VEGF165 is present in human eyes affected by diabetic retinopathy with increased concentration and plays an active role in promoting angiogenesis and in enhancing vascular permeability. The Macugen diabetic retinopathy study was a phase II randomised, sham-controlled, double-masked, dose-finding trial designed to evaluate the effect of three doses of intravitreal pegaptanib versus sham injection in patients affected by clinically significant DME. ${ }^{24}$ One hundred seventy-two patients were randomised to receive $0.3 \mathrm{mg}(n=44), 1.0 \mathrm{mg}(n=44)$, or $3.0 \mathrm{mg}(n=42)$ pegaptanib, or sham injection $(n=42)$, at baseline and at week six and week 12. If needed, additional injections were administered every six weeks up to a maximum of three additional injections. Retinal laser photocoagulation could be delivered if the investigators judged it necessary. At the final visit at week 36, the group of patients receiving pegaptanib $0.3 \mathrm{mg}$ was significantly superior to the sham injection group, as measured by mean change in VA $(+4.7$ letters versus -0.4 letters, $\mathrm{p}=0.04$ ), proportion of patients gaining $>10$ letters of VA (34 versus $10 \%, p=0.003)$, change in mean CRT ( $68 \mu \mathrm{m}$ reduction versus $3.7 \mu \mathrm{m}$ increase, $\mathrm{p}=0.02$ ). Moreover, only $25 \%$ of patients receiving pegaptanib required retinal photocoagulation, in comparison with $40 \%$ of patients receiving sham injection ( $p=0.04)$. Patients receiving 1.0 or $3.0 \mathrm{mg}$ did not show a significant improvement compared with $0.3 \mathrm{mg}$ as regards BCVA or CRT changes. Adverse events were noted in all treatment arms and were transient, procedure-related and mild or moderate (such as eye pain, vitreous floaters, eye discharge and conjunctival haemorrhage).

Recently, the results of a sham-controlled, multicentre, parallel-group study were reported. ${ }^{25}$ The aim of this study was to demonstrate the efficacy of $0.3 \mathrm{mg}$ pegaptanib intravitreal injection to improve VA more than 10 Early treatment of diabetic retinopathy study (ETDRS) letters from baseline compared with sham injection. During the study, focal/grid laser photocoagulation was allowed, starting at week 18, if necessary. Two hundred and sixty and 207 patients, respectively, concluded one or two years of follow-up. The authors reported an improvement in VA $\geq 10$ ETDRS letters at week 54 in $36.8 \%$ of subjects in the pegaptanib group and in $19.7 \%$ of the sham group compared with baseline values. A better VA in the pegaptanib group was also reported at the end of the two-year follow-up period. Moreover, fewer pegaptanib-treated subjects received laser treatment compared with sham-treated subjects (23.3 versus $41.7 \%$ at week $54,25.2$ versus $45.0 \%$ at week 102). The incidence of adverse events was lower in the pegaptanib group compared with the sham group.

\section{Bevacizumab}

Bevacizumab is a full-length recombinant humanised antibody active against all isoforms of VEGF. Short-term effects of bevacizumab for 
DME in a large randomised Phase II clinical trial were initially reported by the DRCRnet. ${ }^{26}$ One hundred nine subjects with DME and Snellen acuity equivalent ranging from 20/32 to 20/320 were prospectively enrolled and randomised to five groups:

- focal photocoagulation at baseline;

- intravitreal injection of $1.25 \mathrm{mg}$ bevacizumab at baseline and six weeks;

- intravitreal injection of $2.5 \mathrm{mg}$ bevacizumab at baseline and six weeks

- intravitreal injection of $1.25 \mathrm{mg}$ bevacizumab at baseline and sham injection at six weeks; or

- intravitreal injection of $1.25 \mathrm{mg}$ bevacizumab at baseline and six weeks with photocoagulation at three weeks.

The BCVA in the groups receiving bevacizumab alone showed a median one-line improvement at the three-week visit, which was preserved up to 12 weeks and was greater than the change in the group receiving only focal photocoagulation at baseline. A similar trend was observed in regard to CRT: comparing focal photocoagulation versus bevacizumab alone, a greater reduction in CRT was observed in the bevacizumab groups at three weeks. No significant differences in changes in BCVA or CRT between groups receiving bevacizumab 1.25 versus $2.5 \mathrm{mg}$ were observed. Comparing bevacizumab groups with groups receiving combined treatment, no significant differences were observed in reduction of central subfield thickening or improvement in VA.

Lam et al. evaluated the efficacy of two dosing regimens of bevacizumab at six months of follow-up. ${ }^{27}$ Forty-eight patients were randomised to receive three monthly intravitreal injections of $1.25 \mathrm{mg}$ $(n=23)$ or $2.5 \mathrm{mg}(n=25)$ bevacizumab. At each monthly scheduled visit a significant mean CFT reduction was observed in both groups. Similarly, the mean logarithm of the minimum angle of resolution (logMAR) BCVA showed a statistically significant improvement from the baseline to final visit at six months (from 0.63 to 0.52 in the $1.25 \mathrm{mg}$ group; from 0.60 to 0.47 in the $2.5 \mathrm{mg}$ group). No significant difference in BCVA was observed between the two groups. No significant adverse events were reported during the study. Arevalo et al. reported the results of a retrospective, multicentre, interventional, comparative case series with a long-term follow-up extended to 24 months. ${ }^{28}$ The study evaluated 139 eyes receiving bevacizumab intravitreal injection (1.25 mg [ $n=74]$ or $2.5 \mathrm{mg}[n=65])$. Additional injections were administered if recurrence of macular oedema was detected on OCT associated with VA loss. At one month, both groups showed a statistically significant improvement in BCVA and subsequently the gain was preserved up to the 24-months examination. The $1.25 \mathrm{mg}$ group improved from 20/150 to 20/107 at one month and to 20/75 at 24 months. In the 2.5 mg group, the BCVA improved from 20/168 to 20/118 at one month and to 20/114 at the final visit.

Long-term efficacy of repeated injections of intravitreal bevacizumab $1.25 \mathrm{mg}$ for the treatment of chronic DME was also reported by Kook et al. ${ }^{29}$ The study (prospective, consecutive, non-comparative case series) included 126 patients affected by chronic, diffuse, clinically significant DME in part not responsive to previous treatments. Preceding treatments included focal laser treatment (62 \%), triamcinolone intravitreal injection (41\%), panretinal laser treatment (38\%), or vitrectomy (11\%). Sixty-seven and 59 patients completed the scheduled visits to six months and 12 months, respectively. At the six-month examination, the IogMAR BCVA ranged from baseline value of 0.82 to 0.74 , considering all patients. The mean BCVA of patients who completed the 12-month follow-up improved similarly, from 0.82 to $0.74 \operatorname{logMAR}$. Mean CRT decreased from 463 to $374 \mu \mathrm{m}$ after six months and to $357 \mu \mathrm{m}$ after 12 months with a statistically significant difference. This study showed that, even in cases with chronic diffuse ischaemic DME not responding to other therapy, a successful treatment with repeated intravitreal injections of bevacizumab can be achieved over a long-term follow-up period.

Other studies compared intravitreal bevacizumab treatment with intravitreal triamcinolone or focal retinal photocoagulation in refractory DME or as primary treatment. Paccola et al. designed a randomised, prospective study in order to evaluate the anatomical response and VA outcomes after a single intravitreal injection of triamcinolone acetonide (4 mg) or bevacizumab (1.25 mg) in refractory diffuse DME. ${ }^{30}$ The study enrolled 26 patients; at baseline, the IogMAR BCVA was 0.936 and 0.937 in the triamcinolone and bevacizumab groups, respectively. At six months, the BCVA improved to 0.91 and 0.92 without achieving a significant difference; however, interim analysis at one-, two- and three-month examinations evidenced a significant improvement in the triamcinolone group compared with the bevacizumab group.

A similar prospective and comparative case series was reported by Shimura et al. ${ }^{31}$ The study recruited 14 patients with bilateral long-standing DME; in each patient, one eye was selected to receive a single intravitreal injection of triamcinolone $(4 \mathrm{mg}$ ) and the other to receive a single intravitreal bevacizumab injection $(1.25 \mathrm{mg})$. The IOgMAR BCVA in the triamcinolone group improved significantly from 0.64 to 0.33 at one week, and the gain was subsequently preserved up to 12 weeks. At a final observation period of 24 weeks, BCVA decreased to 0.47 but was still significantly different from the baseline value. Similarly, BCVA in the bevacizumab group improved from 0.61 to 0.39 at one week and maintained the initial gain up to four weeks. At 12 weeks, BCVA returned to the initial level. No further decrease or improvement was observed in the following three months. A statistically significant difference in BCVA was observed in favour of the triamcinolone group at three and six months.

A randomised, three-arm clinical trial comparing intravitreal bevacizumab injection (1.25 $\mathrm{mg}, \mathrm{n}=50$ ), alone or in combination with intravitreal triamcinolone acetonide ( $\mathrm{mg}, \mathrm{n}=50$ ), versus macular laser photocoagulation $(n=50)$ as a primary treatment of DME was published by Soheilian et al. ${ }^{32}$ The bevacizumab group showed a significant BCVA improvement, from 0.71 to 0.54 at six weeks; the initial gain was maintained in each following visit at 12,24 , and 36 weeks. The patients that underwent combined treatment showed a significant BCVA improvement, from 0.73 to 0.60 at six weeks. This group showed stability of BCVA at 12 weeks but loss of statistically significant improvement at six and nine months. In the macular photocoagulation group, the BCVA showed stabilisation at six weeks in comparison with the baseline value (0.60 versus 0.55 ) and similar values were observed at all follow-up evaluations. However, it is important to note that the three groups differed in regard to the baseline VA values. The mean values of CMT decreased significantly, in comparison with the baseline values, in all groups only at six weeks and although the reduction was greater in the bevacizumab group with respect to the other two groups, no statistically significant difference was registered during follow-up. Recently, the authors categorised the original treatment arms and the following

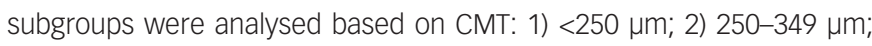
and 3) $\geq 350 \mu \mathrm{m} .{ }^{33}$ Main outcome measures were changes in VA and CMT at weeks six, 12, 24, and 36. At six weeks in all subgroups, mean VA 
improvement in the bevacizumab group was significantly greater than in the other groups. With a longer follow-up, however, bevacizumab turned out to be superior to bevacizumab/triamcinolone and macular laser photocoagulation only in the eyes with initial CMT of $\geq 350 \mu \mathrm{m}$, indicating that in the primary treatment of DME, initial CMT may be an important factor in decision-making.

Recently, the results of a retrospective, multicentre, interventional comparative case series involving 115 consecutive patients (139 eyes) with DME receiving primary treatment with 1.25 or $2.5 \mathrm{mg}$ bevacizumab were published. ${ }^{34}$ Patients received re-injections whenever there was a recurrence of DME (defined by a decrease in BCVA associated with the presence of intraretinal fluid on OCT or fluorescein angiography). In the first month after the initial bevacizumab injection, improvements in BCVA and CMT measurements were recorded and these significant changes continued throughout the 24-month follow-up. BCVA analysis at 24 months showed that 62 (44.6\%) eyes remained stable, 72 (51.8\%) eyes improved by two or more ETDRS lines and five (3.6\%) eyes decreased by two or more ETDRS lines.

The one-year results of a prospective randomised trial were recently reported..$^{35}$ The Bevacizumab or laser therapy in the management of diabetic macular edema (BOLT) study recruited 80 patients (80 eyes) affected by centre-involving clinically significant DME and at least one previous macular laser treatment. Subjects were randomised to two groups receiving intravitreal bevacizumab $(n=42)$ or laser treatment according to ETDRS guidelines $(n=38)$. Subjects in the bevacizumab arm underwent an injection at their baseline visit (1.25 mg in $0.05 \mathrm{ml}$ ). Patients were reviewed every six weeks with an end-of-year visit at 52 weeks. After the baseline injection, patients received two further injections at six and 12 weeks. Additional injections were programmed according to a specific OCT-based retreatment protocol. Subjects in the laser arm underwent modified ETDRS laser treatment at their baseline visit and were reviewed every four months with an end-of-year visit at 52 weeks. Retreatment was performed according to ETDRS guidelines. The primary endpoint was the difference in ETDRS BCVA at 12 months between the two arms. The baseline characteristics of the two treatment groups were comparable; the only significant difference in the groups was the duration of DME (median of 24 and 36 months in the bevacizumab and laser arms, respectively). Two patients in the laser group did not complete the 12 months of follow-up, while all 42 patients in the bevacizumab arm completed the study. The bevacizumab group gained a median of eight ETDRS letters, compared with the laser group which lost 0.5 ETDRS letters ( $p=0.0002$ ). Mean CRT changes from baseline were -130 and -67 in the bevacizumab and laser groups, respectively $(p=0.06)$. The median number of treatments was nine in the bevacizumab arm and three in the laser treatment arm. The findings of this study support the use of bevacizumab for DME. However, to confirm these results a larger trial with a longer follow-up period and a treatment arm that includes laser + bevacizumab therapy is needed.

\section{Vascular Endothelial Growth Factor Trap}

VEGF Trap-Eye (Regeneron) is a $115 \mathrm{kDa}$ recombinant fusion protein of portions of VEGF receptors 1 and 2 and the FC region of human immunoglobulin-G (IgG) which binds all VEGF-A isoforms with higher affinity in comparison with other anti-VEGF substances, including bevacizumab and ranibizumab. ${ }^{36}$ Moreover, VEGF Trap-Eye has a longer half-life in the eye after intraocular injection and it binds other members of the VEGF family including placental growth factors 1 and 2, which have been shown to determine excessive vascular permeability. This higher affinity will most probably allow lower doses to be employed and a longer duration of action to be maintained. ${ }^{37,38}$ A Phase I study exploring the safety and bioactivity of a single injection of $4.0 \mathrm{mg}$ VEGF Trap-Eye in subjects with DME demonstrated a reduction in CRT and significant improvement in VA. ${ }^{39}$ In a recent study, 221 diabetic patients with DME were enrolled and assigned to five different groups characterised by different dosing regimens of intravitreal VEGF Trap (monthly injection of 0.5 or 2 mg VEGF Trap, three monthly injections followed by other injections every eight weeks or on PRN regimen, or macular laser photocoagulation alone). ${ }^{40}$ The four VEGF Trap groups gained from 8.5 to 11.4 ETDRS letters versus only 2.5 letters in the laser group ( $p=0.0085$ ) and obtained a reduction in CRT by 127.3-194.5 $\mu \mathrm{m}$, compared with the $67.9 \mu \mathrm{m}$ of the laser group $(p=0.0066)$.

\section{Bevasiranib}

Small interfering RNA (siRNA) molecules are able to inactivate mRNA and suppress RNA translation. Bevasiranib is a specific siRNA designed to reduce the levels and activity of VEGF mRNA and may have a role in the treatment of diabetic retinopathy. ${ }^{41-43}$ The RNAi assessment of bevasiranib in diabetic macular edema (RACE) trial investigated the use of different doses of bevasiranib $(0.2,1.5$, or $3.0 \mathrm{mg})^{44}$ administered monthly for three months. The study showed a reduction in macular thickness between weeks 8 and 12 and improvement of VA. A Phase III, randomised, double-masked clinical trial evaluating the efficacy of bevasiranib in patients affected by wet age-related macular degeneration was recently terminated. Subjects received bevasiranib either every eight weeks or every 12 weeks after an initial pre-treatment with three injections of ranibizumab, compared with ranibizumab given every four weeks. Preliminary results after 60 weeks suggest that bevasiranib is efficacious, even though slightly inferior to ranibizumab. Average VA remained positive through week 60 and a lower proportion of patients avoided visual loss on the more frequent bevasiranib dosing arm. ${ }^{45}$ Results from randomised clinical trials evaluating the use of bevasiranib in the treatment of DME are awaited.

\section{Rapamycin}

Rapamycin (also known as sirolimus) is a macrocyclic antibiotic (produced by Streptomyces hygroscopicus) that specifically binds FK-binding protein-12 (FKBP12); the active complex inhibits the mammalian target of rapamycin (MTOR), a kinase which integrates growth factor-activated signals, including signals that promote angiogenesis mediated by VEGF. Moreover, mTOR is an activator of hypoxia-inducible factor-1a (HIF-1a), which upregulates the transcription of VEGF. In hypoxic cells, rapamycin can interfere with HIF-1a activation by increasing the rate of its degradation. ${ }^{46-48}$ Therefore, rapamycin may have a meaningful role as therapy for retinal disorders characterised by pathological vascular permeability and proliferation. Preliminary results of the application of rapamycin for DME were presented at the Association of Research in Vision and Ophthalmology (ARVO) Meeting 2008 by Blumenkranz et al. ${ }^{49}$ showing a significant improvement in BCVA and CRT reduction. The most recent results come from a Phase I/II prospective, open-label pilot study ${ }^{50}$ Five adult participants with DME involving the centre of the fovea and best corrected ETDRS VA score of $\leq 74$ letters received $20 \mu \mathrm{l}$ (440 $\mu \mathrm{g}$ ) of subconjunctival rapamycin at baseline, month two, and every two months thereafter, unless there was resolution of either retinal thickening on OCT or leakage on fluorescein angiography. The main outcomes were BCVA, CRT and safety outcomes. The results 
from this trial suggest that subconjunctival rapamycin is safe in the treatment of patients with $\mathrm{DME}$; however, conclusions cannot be drawn regarding its therapeutic efficacy in DME, since the findings could also be attributed to the natural history of DME or laser treatment. In order to demonstrate the possible therapeutic effect of rapamycin a large randomised clinical trial must be designed.

\section{Conclusions}

VEGF plays a key role in promoting angiogenesis and vascular leakage and today represents an attractive candidate as a therapeutic target in the treatment and management of diabetic retinopathy. The advent of intravitreal anti-VEGF drugs has opened a new era for the management of DME. While focal/grid laser remains a standard treatment for DME and is supported by evidence provided by large-scale studies, ${ }^{51}$ the use of anti-VEGF substances in clinical practice has showed encouraging results. Most of the studies reported in this article were well-designed clinical trials with the objective of demonstrating both the therapeutic effect of anti-VEGF drugs and data regarding their safety. However, only larger trials can consolidate the use of anti-VEGF drugs in the clinical routine with the objective of creating guidelines for the management of DME. Another aspect that must be highlighted is the efficacy of anti-VEGF drugs over longer follow-up periods. Most controlled studies focus on one- or two-year results, but long-term results are unavailable. It would be of the utmost importance to demonstrate that anti-VEGF drugs are able to provide therapeutic effects over a long period of time, and to compare these effects with those of laser treatment, which is characterised by a slow, but sustained therapeutic effect that most likely is more efficient many years after its employment. The use of combination therapy including anti-VEGF and focal/grid laser treatment has provided encouraging results and must also be evaluated over a long timespan. In particular, the combination of laser application and intravitreal anti-VEGF can reduce the number of injections without a negative effect on visual function, in an attempt to lessen the burden of the therapy for both patients and doctors.

Different clinical trials have demonstrated an adequate safety profile for anti-VEGF substances, even though a long-term analysis of systemic and ocular side effects is needed. In essence, anti-VEGF drugs have revolutionised the treatment of DME. It is likely that combination treatment with laser photocoagulation can be practical and effective in the management of DME.
1. Kempen $\mathrm{JH}, \mathrm{O}^{\prime}$ Colmain BJ, Leske MC, et al., Eye Diseases Prevalence Research Group, The prevalence of diabetic retinopathy among adults in the United States, Arch Ophthalmol retinopathy among $122: 552-63$.

2. Klein $R$, Retinopathy in a population-based study, Trans Am Ophthalmol Soc, 1992;90:561-94.

3. Orchard TJ, Dorman JS, Maser RE, et al., Prevalence of complications in IDDM by sex and duration. Pittsburgh Epidemiology of Diabetes Complications Study II, Diabetes, 1990;39:1116-24.

4. Wild S, Roglic G, Green A, et al., Global prevalence of diabetes: estimates for the year 2000 and projections for 2030, Diabetes Care, 2004;27:1047-53.

5. Bandello F, Parodi MB, Lanzetta P, et al., Diabetic macular edema, Dev Ophthalmol, 2010;47:73-110.

6. Neufeld G, Cohen T, Gengrinovitch S, Poltorak Z, Vascular endothelial growth factor (VEGF) and its receptors, FASEB J, 1999;13:9-22.

7. Grant MB, Afzal A, Spoerri P, et al., The role of growth factors in the pathogenesis of diabetic retinopathy, Expert Opin Investig Drugs, 2004;13:1275-93.

8. Plate $\mathrm{KH}$, Breier G, Weich HA, Risau W, Vascular endothelial growth factor is a potential tumour angiogenesis factor in human gliomas in vivo, Nature, 1992:359:845-8.

9. Shweiki D, Itin A, Soffer D, Keshet E, Vascular endothelial growth factor induced by hypoxia may mediate hypoxia-initiated angiogenesis, Nature, 1992;359:843-5.

10. Aiello LP, Avery RL, Arrigg PG, et al., Vascular endothelial growth factor in ocular fluid of patients with diabetic retinopathy and other retinal disorders, $N$ Engl J Med, 1994;331:1480-7

11. Gardner TW, Antonetti DA, Barber AJ, et al., Diabetic retinopathy: more than meets the eye, Surv Ophthalmol 2002;47(Suppl. 2):S253-62

12. Chun DW, Heier JS, Topping TM, et al., A pilot study of multiple intravitreal injections of ranibizumab in patients with center-involving clinically significant diabetic macular edema, Ophthalmology, 2006;113:1706-12.

13. Nguyen QD, Tatlipinar S, Shah SM, et al., Vascular endothelial growth factor is a critical stimulus for diabetic macular edema Am J Ophthalmol, 2006;142:961-9.

14. Nguyen QD, Shah SM, Heier JS, et al., Primary End Point (Six Months) Results of the Ranibizumab for Edema of the mAcula in diabetes (READ-2) study, Ophthalmology, 2009;116:2175-81.e1

15. Nguyen QD, Shah SM, Khwaja AA, et al., READ-2 Study Group. Two-year outcomes of the ranibizumab for edema of the mAcula in diabetes (READ-2) study, Ophthalmology, 2010;117:2146-51

16. Wolf $S$, Massin P, Bandello F, et al., RESOLVE Study Group. Safety and Efficacy of Ranibizumab Treatment in Patients With Diabetic Macular Edema: 12-Months Results of the Resolve Study, Presented at: Association for Research in Vision and Ophthalmology Meeting, Fort Lauderdale, FL, May 2-7, 2009.

17. Massin P, Bandello F, Garweg JG, et al., Safety and efficacy of ranibizumab in diabetic macular edema (RESOLVE Study): a 12-month, randomized, controlled, double-masked, multicente 12-month, randomized, controlled, double-maske

18. Mitchell $P$, Bandello $F$, Schmidt-Erfurth $U$, et al., The RESTORE study: ranibizumab monotherapy or combined with laser versus laser monotherapy for diabetic macular edema, Ophthalmology, 2011;118:615-25

19. Massin P, Audren F, Haouchine B, et al., Intravitreal triamcinolone acetonide for diabetic diffuse macular edema: preliminary results of a prospective controlled trial, Ophthalmology, 2004;111:218-24.

20. Gillies MC, Sutter FK, Simpson JM, et al., Intravitrea triamcinolone for refractory diabetic macular edema: two-year results of a double-masked, placebo-controlled, randomized clinical trial, Ophthalmology, 2006;113:1533-8.

21. Elman MJ, Bressler NM, Qin $\mathrm{H}$, et al., Expanded 2-year follow-up of ranibizumab plus prompt or deferred laser or triamcinolone plus prompt laser for diabetic macular edema. Diabetic Retinopathy Clinical Research Network, Ophthalmology, 2011;118:609-14.

22. Googe J, Brucker AJ, Bressler NM, et al., Randomized trial evaluating short-term effects of intravitreal ranibizumab or triamcinolone acetonide on macular edema after focal/grid triamcinolone acetonide on macular edema after focal/grid
laser for diabetic macular edema in eyes also receiving panretinal photocoagulation, Retina, 2011;31:1009-27.

23. Two Pivotal Phase III Lucentis Studies Showed Patients With Diabetic Macular Edema Experienced Significant Improvements in Vision and Fewer Developed More Advanced Retinopathy, 2011. Available at: www.gene.com (accessed 28 June 2011).

24. Cunningham ET Jr, Adamis AP, Altaweel M, et al., Macugen Diabetic Retinopathy Study Group. A phase II randomized double-masked trial of pegaptanib, an anti-vascular endothelia growth factor aptamer, for diabetic macular edema growth factor aptamer, for diabetic
Ophthalmology, 2005:112:1747-57.

25. Sultan MB, Zhou D, Loftus J, et al., A phase 2/3, multicenter, randomized, double-masked, 2-year trial of pegaptanib sodium for the treatment of diabetic macular edema, Ophthalmology, 2011;118:1107-18.

26. Scott IU, Edwards AR, Beck RW, et al., for the Diabetic Retinopathy Clinical Research Network, A phase II randomized clinical trial of intravitreal bevacizumab for diabetic macular edema, Ophthalmology, 2007;114:1860-7.

27. Lam DS, Lai TY, Lee VY, et al., Efficacy of $1.25 \mathrm{MG}$ versus $2.5 \mathrm{MG}$ intravitreal bevacizumab for diabetic macular edema: six-month results of a randomized controlled trial, Retina, 2009;29:292-9

28. Arevalo JF, Sanchez JG, Wu L, et al., Primary intravitreal bevacizumab for diffuse diabetic macular edema: the PanAmerican Collaborative Retina Study Group at 24 months, Ophthalmology, 2009;116:1488-97, 1497.e1.

29. Kook D, Wolf A, Kreutzer T, et al., Long-term effect of intravitreal bevacizumab (avastin) in patients with chronic diffuse diabetic macular edema, Retina, 2008:28:1053-60.

30. Paccola L, Costa RA, Folgosa MS, et al., Intravitreal triamcinolone versus bevacizumab for treatment of refractory diabetic macular oedema (IBEME study), Br J Ophthalmol, 2008;92:76-80.

31. Shimura M, Nakazawa T, Yasuda K, et al., Comparative therapy evaluation of intravitreal bevacizumab and triamcinolone acetonide on persistent diffuse diabetic macular edema, Am 」 Ophthalmol, 2008;145:854-61

32. Soheilian M, Ramezani A, Obudi A, et al., Randomized trial of intravitreal bevacizumab alone or combined with triamcinolon intravitreal bevacizumab alone or combined with triamcinolone
versus macular photocoagulation in diabetic macular edema, Ophthalmology, 2009;116:1142-50

33. Soheilian M, Ramezani A, Yaseri M, et al., Initial macular thickness and response to treatment in diabetic macular edema, Retina, 2011;31:1564-73.

34. Arevalo JF, Sanchez JG, Lasave AF, et al., Intravitrea Bevacizumab (Avastin) for Diabetic Retinopathy: The 2010
GLADAOF Lecture, J Ophthalmol, 2011;2011:584238.

35. Michaelides M, Kaines A, Hamilton RD, et al., A prospective randomized trial of intravitreal bevacizumab or laser therapy in the management of Diabetic Macular Edema (BOLT Study). 12 Month data: Report 2, Ophthalmology, 2010;117:1078-86.

36. Economides AN, Carpenter LR, Rudge JS, et al., Cytokine traps: multi-component, high-affinity blockers of cytokine action, Nat Med, 2003;9:47-52.

37. Holash J, Davis S, Papadopoulos N, et al., VEGF-Trap: a VEGF blocker with potent antitumor effects, Proc Natl Acad Sci USA, 2002;99:11393-8.

38. Stewart MW, Rosenfeld PJ, Predicted biological activity of intravitreal VEGF Trap, Br $J$ Ophthalmol, 2008:92:667-8.

39. Do DV, Nguyen QD, Shah SM, et al., An exploratory study of the safety, tolerability and bioactivity of a single intravitreal injection of vascular endothelial growth factor trap-eye in patients with diabetic macular oedema, Br J Ophthalmol, 2009;93:144-9.

40. Do DV, Schmidt-Erfurth U, Gonzalez VH, et al., The DA VINCI Study: phase 2 primary results of VEGF Trap-Eye in patients with diabetic macular edema, Ophthalmology, 2011;118(9):1819-26.

41. Reich SJ, Fosnot J, Kuroki A, et al., Small interfering RNA (siRNA) targeting VEGF effectively inhibits ocular neovascularization in a mouse model, Mol Vis, 2003;9:210-6.

42. Shen J, Samul R, Silva RL, et al., Suppression of ocular neovascularization with siRNA targeting VEGF receptor 1 , Gene Ther, 2006;13:225-34.

43. Singerman $\mathrm{L}$, Combination therapy using the small interfering RNA bevasiranib, Retina, 2009;29(6 Suppl.):S49-50.

44. Singerman $\sqcup$, Intravitreal bevasiranib in exudative age-related macular degeneration or diabetic macular edema, Presented at: 25th Annual Meeting of the American Society of Retina Specialists, Indian Wells, CA, 1-5 December 2007.

45. A Phase 3, Randomized, Double-masked, Parallel-assignment Study of Intravitreal Bevasiranib Sodium, Administered Every 8 or 12 Weeks as Maintenance Therapy Following Three Injections of Lucentis Compared With Lucentis Monotherapy Every 4 Weeks in Patients With Exudative Age-Related Macular Degeneration (AMD). ClinicalTrials.gov identifier NCT00499590

46. Sausville EA, Elsayed Y, Monga M, Kim G, Signal transductiondirected cancer treatments, Annu Rev Pharmacol Toxicol, 2003;43:199-231.

47. Guba M, von Breitenbuch P, Steinbauer M, et al., Rapamycin inhibits primary and metastatic tumor growth by antiangiogenesis: involvement of vascular endothelial growth factor, Nat Med, 2002;8:128-35.

48. Sehgal SN, Rapamune (RAPA, rapamycin, sirolimus): mechanism of action immunosuppressive effect results from blockade of signal transduction and inhibition of cell cycle progression, Cli Biochem, 1998;31:335-40.

49. Blumenkranz MS, Dugel PU, Solley WA, et al., A Randomized Dose-Escalation Trial of Locally-Administered Sirolimus to Treat Diabetic Macular Edema, Presented at: Association of Research in Vision and Ophthalmology Annual Meeting, Fort Lauderdale, Florida, US, 27 April-1 May 2008.

50. Krishnadev N, Forooghian F, Cukras C, et al., Subconjunctival sirolimus in the treatment of diabetic macular edema, Graefes Arch Clin Exp Ophthalmol, 2011;249:1627-33.

51. ETDRS Research Group, Treatment techniques and clinical guidelines for photocoagulation of diabetic macular edema. Early Treatment Diabetic Retinopathy Study Report Number 2. Early Treatment Diabetic Retinopathy Study Research Group, Ophthalmology, 1987;94:761-74. 